\title{
Heat Sponge: A Concept for Mass-Efficient Heat Storage
}

\author{
Scott C. Splinter, Max L. Blosser \\ NASA Langley Research Center \\ Hampton, VA
}

\author{
Andrew R. Gifford \\ Virginia Polytechnic Institute and State University \\ Blacksburg, VA
}

\begin{abstract}
\section{Introduction}

Hypersonic and re-entry vehicles experience extreme aero-thermodynamic heating which requires the use of Thermal Protection Systems (TPS) to survive and regulate the heat transfer to and from the vehicle in order to maintain structural integrity. Detailed studies of the thermal performance of insulating TPS concepts by Myers et al. [1] and Blosser [2] found that the heat capacity of the vehicle structure is one of the most influential factors determining TPS thermal performance. An increase in heat capacity of the vehicle structure would allow it to absorb more of the incident heat load without exceeding its structural temperature limit. Therefore a thinner, lighter insulator could be applied because it does not have to inhibit as much of the incident heat load [1]. Previous design processes focused on optimizing the weight of the insulation material and sizing it to limit the temperature of whatever structure was selected by the structural designers. Options for enhancing the specific heat capacity of the vehicle structure have been investigated by Blosser [3], leading to the concept of a mass-efficient, heat-storage device called the heat sponge. Figure 1 shows a sketch of a generic heat sponge pressure vessel containing a liquid-vapor mixture. By containing the liquid-vapor mixture within a number of miniature pressure vessels they can be embedded within a variety of different types of structures for heat capacity enhancement.
\end{abstract}

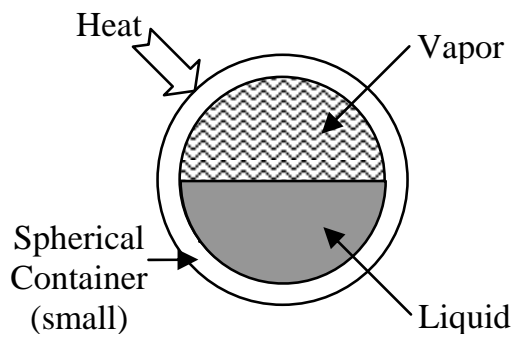

Figure 1. Heat sponge concept 
Different effective heat capacities can be obtained by varying the initial interior volume percentage of the liquid and by varying the type of liquid used. This allows the heat sponge to be optimized to achieve different efficiencies per unit mass or volume. As temperature is increased, pressure in the miniature pressure vessels also increases so that heat absorbed through vaporization of the liquid is spread over a relatively large temperature range. Using water as a working fluid, the heat storage capacity of the liquid-vapor mixture is many times higher than that of typical structural materials and is well above that of common phase change materials over the temperature range of $660^{\circ} \mathrm{R}$ to $1160^{\circ} \mathrm{R}$. Figure 2 shows the different specific heat capacities of an encapsulated liquid-vapor water mixture, excluding the container, with the specific heat capacity of Lithium as it changes phases from solid to liquid at $820^{\circ} \mathrm{R}$. The use of pure ammonia as the working fluid provides a range of application between $432^{\circ} \mathrm{R}$ and $730^{\circ} \mathrm{R}$, or the use of the more practical waterammonia solution provides a range of application between $432^{\circ} \mathrm{R}$ and $1160^{\circ} \mathrm{R}$ or inbetween that of water and pure ammonia. Figure 3 shows the different specific heat capacities of water and pure ammonia for different interior volumetric fill percents. These two working fluids alone provide a broad range of applications for this concept from near cryogenic to high temperature. (Fig 3 . will be fixed by $3^{\text {rd }}$ party.)

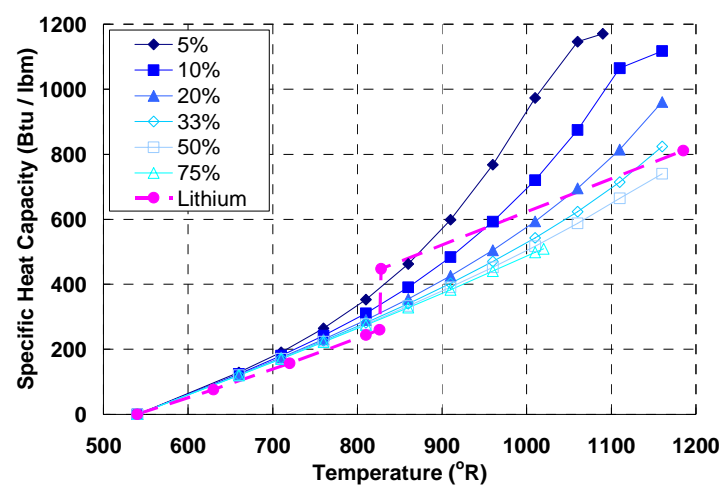

Figure 2. Liquid-vapor water mixture heat capacity percentages Vs. Lithium

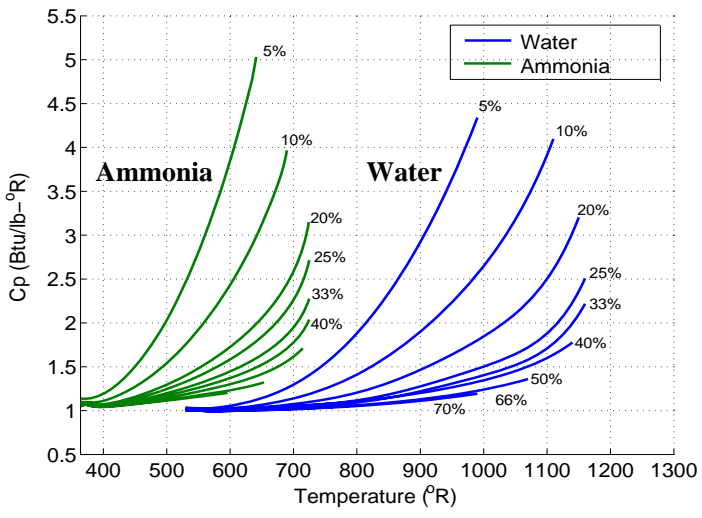

Figure 3. Liquid-vapor ammonia and water mixture heat capacities

\section{Heat Sponge Prototypes}

Heat sponge prototypes were designed and developed to assess the feasibility of the concept. These heat sponge prototypes consisted of 1.0-inch-diameter hollow stainless steel spheres with a wall thickness of 0.020 inches which had varying percentages of their interior volumes filled with water or a water-ammonia solution. These spheres provided prototypes that were large enough to be easily filled, instrumented, and handled, yet small enough to limit the stored energy and influence of the container on the overall effective specific heat capacity. These prototypes were then instrumented with six type $\mathrm{T}$ thermocouples and one strain gauge. Figure 4 shows the progression of the heat sponge prototypes from a hemisphere, to a sphere, to an instrumented sphere with an epoxy patch [4,5]. 


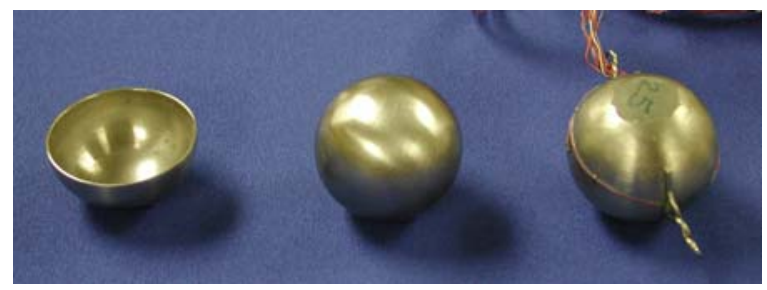

Figure 4. Heat sponge prototypes

\section{Characterization Approach}

The primary limitations in using available heat capacity characterization methods for characterizing the heat sponge prototype were its physical properties; its size, shape, and mass, coupled with its internal liquid-vapor phase change. Therefore a new hybrid technique and apparatus were designed for the characterization of the heat sponge prototype's heat capacity. The apparatus, which was housed in a vacuum chamber, consisted of a heating chamber, cooling chamber, stepper motor, and ceramic thread. The apparatus and method were designed to limit the testing environment down to a single mode of heat transfer, radiation, to simplify the analysis of test data. The test article would be heated uniformly to an elevated temperature in the heating chamber using a coiled cable heater, and then transferred via a ceramic thread, stepper motor, and pulley system to a cooling chamber maintained at a constant temperature by a re-circulating chiller. The temperatures of the cooling chamber and test article were recorded at this time to capture the cool down of the test article. Temperatures and strains recorded during the cool down were used to determine the temperature dependent specific heat capacity and internal pressure of the heat sponge prototypes. The apparatus is shown in Figure 5 [4,5].
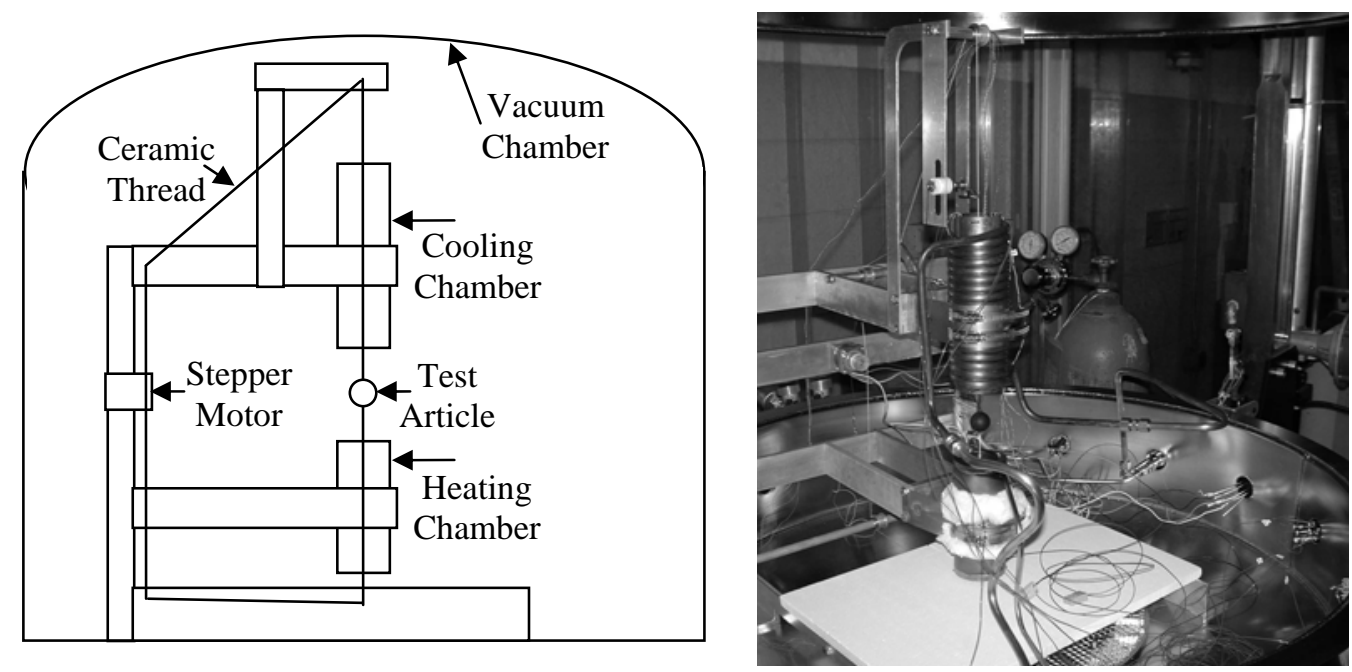

Figure 5. Heat sponge heat capacity characterization apparatus 


\section{Numerical Models}

Numerical models were developed both to predict and to evaluate the performance of the heat sponge concept and will be described in this paper [4,5]. Experimental temperature data was analyzed using a heat transfer model based on a gray enclosure surrounding a gray body and the conservation of energy relation to determine temperature dependent specific heat capacity. Experimental strain data was analyzed using the equations for a thin-walled spherical pressure vessel to determine pressure. A thermodynamic model for an encapsulated liquid-vapor water mixture was developed using thermodynamic properties from the steam tables and the physical constraints of the encapsulated system [6,7]. A thermodynamic model for an encapsulated liquid-vapor water-ammonia mixture was developed using thermodynamic properties determined by the Helmholtz Free Energy (HFE) formulation and the thermodynamic model developed for water [8]. An uncertainty analysis was also performed on the experimental data, and uncertainty values are included in the reporting of the results.

\section{Aluminum Calibration Experiments}

The specific heat capacity of a 1.0-inch-diameter solid aluminum 2024 sphere was characterized first using this new method and apparatus in order to calibrate the equipment and validate the method. Aluminum 2024 was chosen because it has a high specific heat capacity for a structural material, and is inexpensive and readily available. Four series of tests were performed by Splinter [4] and Gifford [5] with this calibration sphere for temperatures between $860^{\circ} \mathrm{R}$ and $500^{\circ} \mathrm{R}$. Representative results from the fourth test series are presented in Figure 6 and Table I. Figure 6 is a plot of the experimental values overlaid with the handbook values with bands denoting the uncertainty in the experimental measurement. Table I displays the average Cp value, average RMS deviation of experimental value from handbook value, and the average uncertainty in the experimental measurement for the aluminum sphere at each of the listed temperatures.

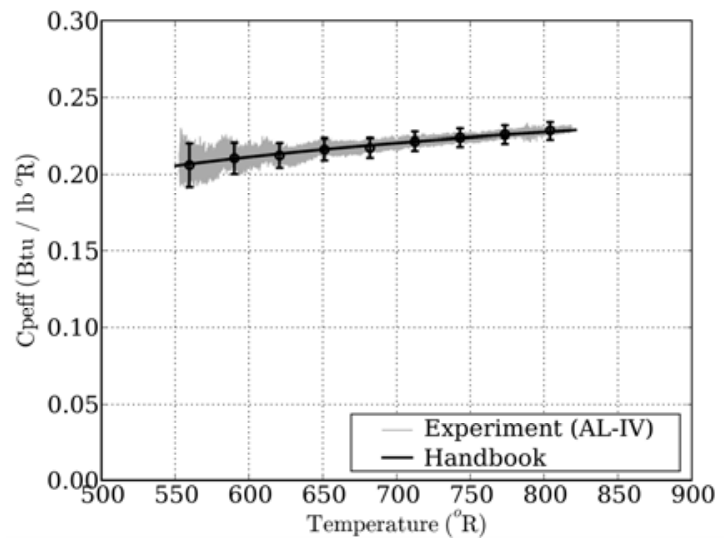

TABLE I. AL 2024 SPECIFIC HEAT CAPACITY RESULTS

\begin{tabular}{|c|c|c|c|}
\hline $\begin{array}{c}\text { Temp. } \\
\left({ }^{\circ} \mathrm{R}\right)\end{array}$ & $\begin{array}{c}\mathrm{Cp} \\
\left(\mathrm{Btu} / \mathrm{lb}^{\circ} \mathrm{R}\right)\end{array}$ & $\begin{array}{c}\text { RMS Dev. } \\
\left(\mathrm{Btu} / \mathrm{lb}{ }^{\circ} \mathrm{R}\right)\end{array}$ & $\begin{array}{c}\text { Uncertainty } \\
\left(\mathrm{Btu} / \mathrm{lb}^{\circ} \mathrm{R}\right)\end{array}$ \\
\hline 804.01 & 0.2284 & 0.0009 & 0.0056 \\
\hline 773.44 & 0.2260 & 0.0006 & 0.0058 \\
\hline 743.00 & 0.2239 & 0.0009 & 0.0059 \\
\hline 712.33 & 0.2216 & 0.0010 & 0.0062 \\
\hline 681.85 & 0.2174 & 0.0021 & 0.0064 \\
\hline 651.17 & 0.2164 & 0.0017 & 0.0071 \\
\hline 620.65 & 0.2126 & 0.0024 & 0.0082 \\
\hline 590.12 & 0.2107 & 0.0032 & 0.0102 \\
\hline 559.65 & 0.2062 & 0.0054 & 0.0143 \\
\hline
\end{tabular}

Figure 6. AL 2024 specific heat capacity results 


\section{Heat Sponge Experiments}

\section{Water-Filled Heat Sponge}

Experimental specific heat capacity results were obtained using the validated method and apparatus for $10 \%, 20 \%, 33 \%$, and $60 \%$ water-filled, stainless-steel, heat-sponge test articles, and were compared to their respective numerical predictions generated by the theoretical models [4]. The $10 \%, 33 \%$, and $60 \%$ waterfilled test articles were chosen because they transition to one of the final equilibrium states of the heat sponge concept; superheated vapor, saturated mixture, and sub-cooled liquid, respectively. The $20 \%$ and a second $33 \%$ water-filled test article were chosen for additional concept characterization and comparison purposes, respectively, after multiple improvements had been made to the apparatus and method. The results for the second 33\% water-filled test article are presented in Figure 7 and Table II, which are similar to Figure 6 and Table I.

When comparing the mass and specific heat capacity of the 33\% water-filled test article to the aluminum calibration sphere at a temperature near $775^{\circ} \mathrm{R}$, the $33 \%$ water-filled test article had more than one and a half times, $165 \%$, the specific heat capacity of the aluminum calibration test article with less than half, $42 \%$, of its mass. Figure 8 displays the results for the $10 \%, 20 \%$, 33\%, and $60 \%$ water-filled, heat sponge, test articles. These experiments show that by containing the liquidvapor phase change of water inside a spherical pressure vessel, the effective specific heat capacity of the vessel can be raised significantly.

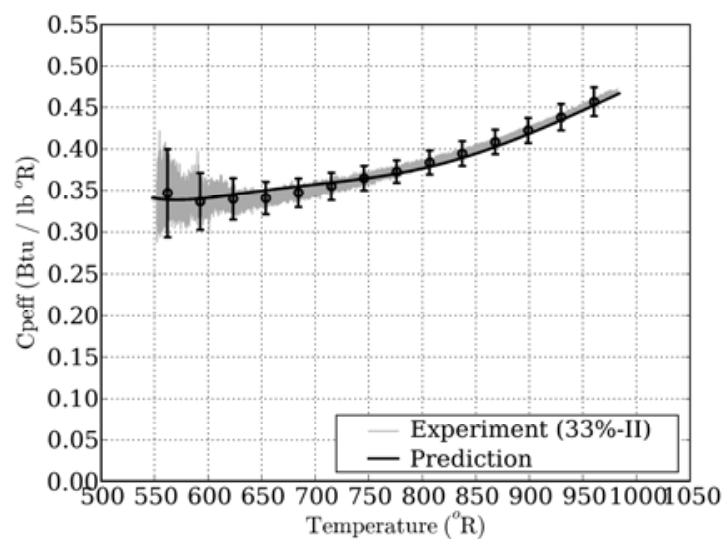

TABLE II. 33\%-II WATER-FILLED SPECIFIC

\begin{tabular}{|c|c|c|c|}
\hline $\begin{array}{c}\text { Hemp } \\
\left({ }^{\circ} \mathrm{R}\right)\end{array}$ & $\begin{array}{c}\mathrm{Cp} \\
\left(\mathrm{Btu} / \mathrm{lb}^{\circ} \mathrm{R}\right)\end{array}$ & $\begin{array}{c}\text { RMS Dev. } \\
\left(\mathrm{Btu} / \mathrm{lb}{ }^{\circ} \mathrm{R}\right)\end{array}$ & $\begin{array}{c}\text { Uncertainty } \\
\left(\text { Btu } / \mathrm{lb}^{\circ} \mathrm{R}\right)\end{array}$ \\
\hline 960.21 & 0.4570 & 0.0049 & 0.0173 \\
\hline 929.41 & 0.4382 & 0.0039 & 0.0158 \\
\hline 898.86 & 0.4224 & 0.0049 & 0.0151 \\
\hline 868.10 & 0.4085 & 0.0064 & 0.0147 \\
\hline 837.31 & 0.3947 & 0.0060 & 0.0148 \\
\hline 806.71 & 0.3838 & 0.0057 & 0.0144 \\
\hline 776.05 & 0.3728 & 0.0035 & 0.0137 \\
\hline 745.53 & 0.3648 & 0.0023 & 0.0148 \\
\hline 714.90 & 0.3550 & 0.0051 & 0.0164 \\
\hline 684.39 & 0.474 & 0.0081 & 0.0171 \\
\hline 653.74 & 0.3409 & 0.0098 & 0.0194 \\
\hline 623.25 & 0.3401 & 0.0072 & 0.0248 \\
\hline 592.68 & 0.3369 & 0.0096 & 0.0341 \\
\hline 562.20 & 0.3470 & 0.0195 & 0.0529 \\
\hline
\end{tabular}

Figure 7. 33\%-II water-filled specific heat capacity results 


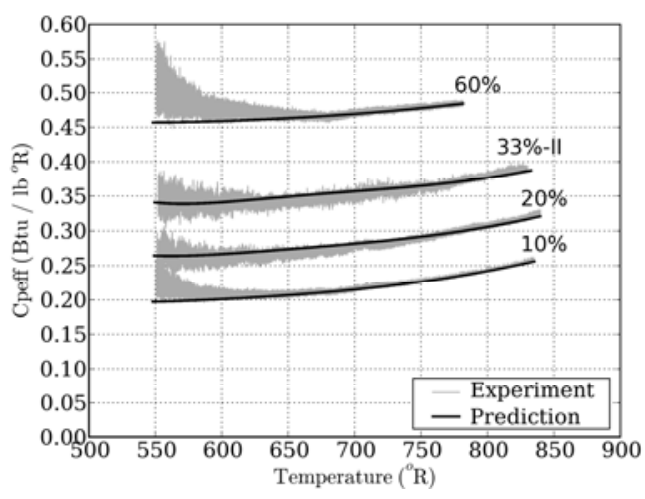

Figure $8.10 \%, 20 \%, 33 \%$, \& 60\% water-filled specific heat capacity results

\section{Water-Ammonia Filled Heat Sponge}

Experimental specific heat capacity results were obtained using the validated method and equipment for three water-ammonia filled, stainless-steel, heat-sponge test articles, and were compared to their respective numerical predictions generated by the theoretical models [5]. The first test article, WA1, had a liquid fill percentage of $50 \%$ and an overall ammonia mass fraction of 0.28 . The second test article, WA2, had a liquid fill percentage of $20 \%$ and an overall ammonia mass fraction of 0.28 . These two test articles were chosen to cover the transition to the final equilibrium states of superheated vapor and sub-cooled liquid for the 0.28 mixture while keeping internal system pressures manageable. The third test article, WA3, had a liquid fill percentage of $50 \%$ and an overall ammonia mass fraction of 0.14. This test article was chosen for comparison with WA1 to demonstrate the effects of changing the overall mass fraction of ammonia for the same liquid fill percentage. The results for the WA1 water-ammonia filled test article are presented in Figure 9 and Table III, which are similar to Figures 6 and 7, and Tables I and II. Results will be discussed for the three water-ammonia test articles, and comparisons to the water filled test articles and alumina calibration sphere will be made.

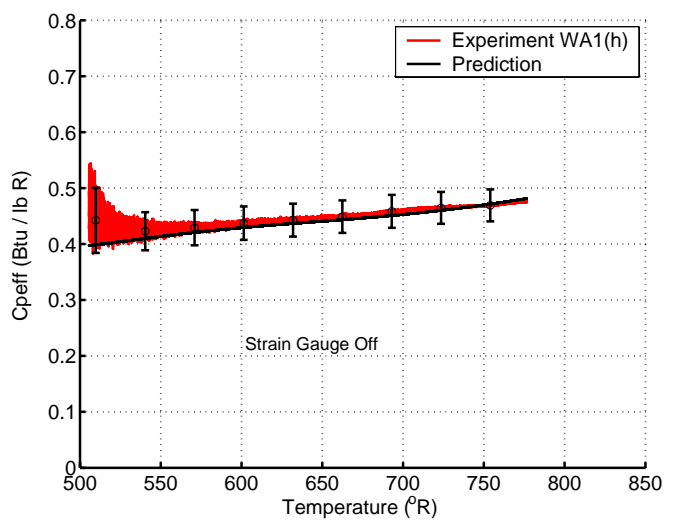

Figure 9. WA1 $\mathrm{H}_{2} \mathrm{O}-\mathrm{NH}_{3}$ specific heat capacity results
TABLE III. WA1 $\mathrm{H}_{2} \mathrm{O}-\mathrm{NH}_{3}$ SPECIFIC HEAT CAPACITY RESULTS

\begin{tabular}{|c|c|c|c|}
\hline $\begin{array}{c}\text { Temp } \\
\left({ }^{\circ} \mathrm{R}\right)\end{array}$ & $\begin{array}{c}\mathrm{Cp} \\
\left(\mathrm{Btu} / \mathrm{lb}^{\circ} \mathrm{R}\right)\end{array}$ & $\begin{array}{c}\text { RMS Dev. } \\
\left(\mathrm{Btu} / \mathrm{lb}{ }^{\circ} \mathrm{R}\right)\end{array}$ & $\begin{array}{c}\text { Uncertainty } \\
\left(\mathrm{Btu} / \mathrm{lb}^{\circ} \mathrm{R}\right)\end{array}$ \\
\hline 753.98 & 0.4691 & 0.0049 & 0.0285 \\
\hline 723.49 & 0.4646 & 0.0039 & 0.0285 \\
\hline 693.01 & 0.4583 & 0.0049 & 0.0294 \\
\hline 662.43 & 0.4489 & 0.0064 & 0.0291 \\
\hline 631.87 & 0.4426 & 0.0060 & 0.0294 \\
\hline 601.38 & 0.4373 & 0.0057 & 0.0298 \\
\hline 570.94 & 0.4292 & 0.0035 & 0.0315 \\
\hline 540.38 & 0.4228 & 0.0023 & 0.0340 \\
\hline 509.79 & 0.4423 & 0.0051 & 0.0582 \\
\hline
\end{tabular}




\section{REFERENCES}

1. Myers, D. E.; Martin, C. J.; and Blosser, M. L.: "Parametric Weight Comparison of Advanced Metallic, Ceramic Tile, and Ceramic Blanket Thermal Protection Systems,” NASA TM-2000-210289, June 2000.

2. Blosser, M. L.: "Advanced Metallic Thermal Protection Systems for Reusable Launch Vehicles,” Ph.D. Dissertation, Dept. of Mechanical and Aerospace Engineering, Univ. of Virginia, Charlottesville, VA, May 2000.

3. Blosser, M. L.: "Heat Sponge - Mass-Efficient Thermal Storage for Multifunctional Structures,” LAR CASE No. 16282-1, Date 3/6/2001. LaRC Invention Disclosure.

4. Splinter, S. C.: "Characterization and Evaluation of a Mass Efficient Heat Storage Device,” Master's Thesis, Dept. of Mechanical and Aerospace Engineering, The George Washington University, Washington D.C., August 2004.

5. Gifford, A. R.: "Further Development of the Heat Sponge Concept Using Water-Ammonia Mixtures,” Master's Thesis, Dept. of Mechanical and Aerospace Engineering, The George Washington University, Washington, D.C., January 2005.

6. Moran, M. J. and Shapiro, H. N., Fundamentals of Engineering Thermodynamics; $4^{\text {th }}$ Ed., 2000, John Wiley \& Sons, New York, NY

7. Keenan, J. H., Keyes, F. G., Hill, P. G., and Moore, J. G., Steam Tables; Thermodynamic Properties of Water Including Vapor, Liquid, and Solid Phases (English Units), 1969, John Wiley Sons, New York, NY

8. Tillner-Roth, R. and Friend, D.G., “A Helmholtz Free Energy Formulation of the Thermodynamic Properties of the Mixture \{Water + Ammonia\}," Journal of Physical and Chemical Reference Data, Vol. 27, No. 1, pp 63-96. 


\title{
Heat Sponge: A Concept for Mass-Efficient Heat Storage
}

\author{
Scott C. Splinter ${ }^{*}$ and Max L. Blosser ${ }^{\dagger}$ \\ NASA Langley Research Center, Hampton, VA 23681 \\ Andrew R. Gifford \\ Virginia Polytechnic Institute and State University, Blacksburg, VA 24061
}

\begin{abstract}
The heat sponge, a mass-efficient heat storage device, was developed to be incorporated into the substructure of a reentry or hypersonic vehicle to reduce thermal protection system requirements. The heat sponge consists of a liquid-vapor mixture contained within a number of miniature pressure vessels that can be embedded within a variety of different types of structures. As temperature is increased, pressure in the miniature pressure vessels also increases so that heat absorbed through vaporization of the liquid is spread over a relatively large temperature range. Using water or pure ammonia as a working fluid, the heat storage capacity of the liquid-vapor mixture is many times higher than that of typical structural materials and is above that of common phase change materials over the temperature range of $432^{\circ} R$ to $1160^{\circ} R$. The use of the more practical water-ammonia solution, which consists of various ratios of water to ammonia, provides a range of application that spans that of water and pure ammonia. Prototype heat sponges were fabricated and characterized. These prototypes consisted of 1.0-inch-diameter hollow stainless steel spheres with a wall thickness of 0.020 inches which had varying percentages of their interior volumes filled with water or water-ammonia solution. An apparatus to measure the heat stored in these prototypes was designed, fabricated, verified, and refined. The calculated heat storage capacities from the apparatus are compared to numerical predictions.
\end{abstract}

\section{Nomenclature}

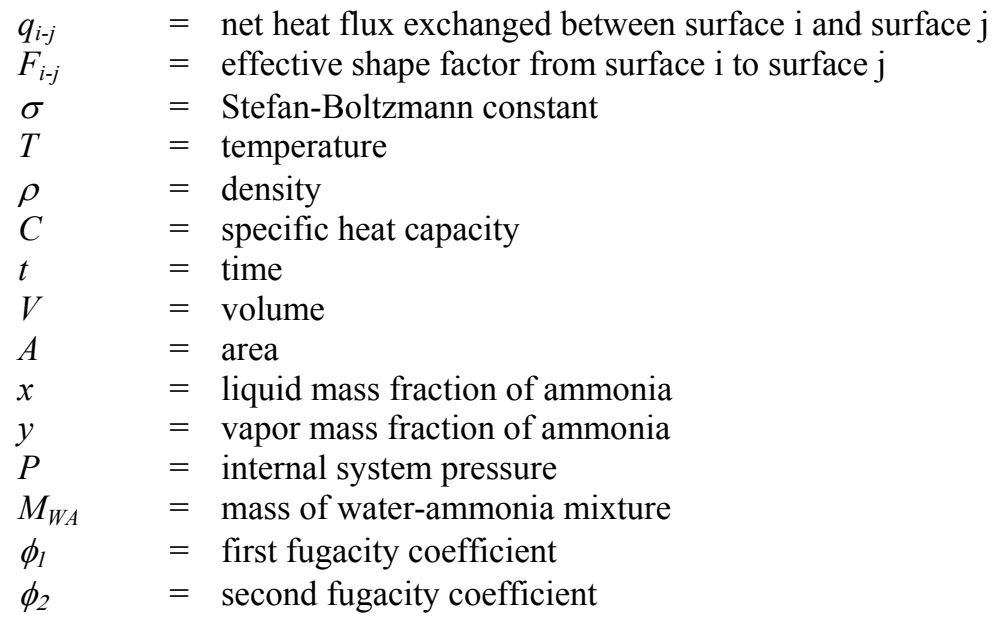

\footnotetext{
${ }^{*}$ Aerospace Engineer, Structural Mechanics and Concepts Branch, MS 190

${ }^{\dagger}$ Aerospace Engineer, Structural Mechanics and Concepts Branch, MS 190

${ }^{\ddagger}$ PhD Student, Department of Mechanical Engineering
}

This material is declared a work of the U.S. Government, and is not subject to copyright protection in the United States. 


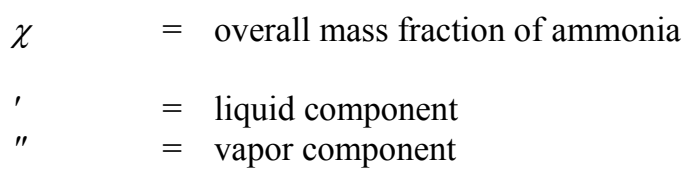

\section{Introduction}

Hypersonic vehicles experience extreme aero-thermodynamic heating which requires the use of Thermal Protection Systems (TPS) to regulate the heat transfer to and from the vehicle in order to maintain structural integrity. Detailed studies of the thermal performance of insulating TPS concepts by Myers ${ }^{1}$ and Blosser ${ }^{2}$ found that the heat capacity of the vehicle structure is one of the most influential factors determining TPS thermal performance. An increase in heat capacity of the vehicle structure would allow it to absorb more of the incident heat load without exceeding its structural temperature limit. Therefore a thinner, lighter insulator could be applied because it does not have to inhibit as much of the incident heat load ${ }^{1}$. This differs from previous design processes which focused on optimizing the insulation material and sizing it to limit the temperature of the structure selected by the structural designers. Options for enhancing the specific heat capacity of the vehicle structure have been investigated by Blosser $^{2}$, Splinter ${ }^{3}$, and Gifford ${ }^{4}$, leading to the concept of a mass-efficient, heat-storage device called the heat sponge.

A number of structural and non-structural materials were investigated by Blosser ${ }^{2}$, Splinter ${ }^{3}$, and Gifford ${ }^{4}$ as candidates for enhancing the heat capacity of structures. Beryllium and Lithium were identified as two materials that had high heat storage capacities, but also had many hazards and drawbacks associated with their use. Liquids were also investigated for use as a heat storage medium, with water and ammonia having the most attractive properties out of the candidates for high and low temperature applications respectively. Water is usually not considered for high temperature applications because it boils at $672^{\circ} \mathrm{R}$. However, by encapsulating the water in a pressure vessel it can be used to store heat at temperatures beyond its boiling point. A further benefit of encapsulation is that it takes advantage of water's high latent heat of vaporization to store additional amounts of heat energy. Likewise, pure ammonia or a water-ammonia solution can be used in the same way. Blosser developed the concept of the heat sponge to contain a liquid-vapor mixture of a fluid within a pressure vessel, or a number of miniature pressure vessels, for the purpose of efficiently absorbing heat ${ }^{3,4}$. Figure 1 shows a sketch of a generic heat sponge pressure vessel containing a liquid-vapor mixture of a fluid. By containing the liquid-vapor mixture within a number of miniature pressure vessels they can be embedded within a variety of different types of structures for heat capacity enhancement.

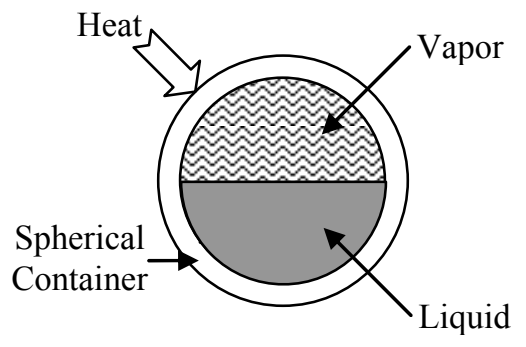

Figure 1. Heat sponge concept

Different effective specific heat capacities can be obtained by varying the initial interior volume percentage of the fluid and by varying the type of fluid used. This allows the heat sponge to be optimized to achieve different efficiencies per unit mass or volume. Using water or pure ammonia as a working fluid, the heat storage capacity of the liquid-vapor mixture is many times higher than that of typical structural materials and is above that of common phase change materials over the temperature range of $432^{\circ} \mathrm{R}$ to $1160^{\circ} \mathrm{R}$. Figure 2 shows the different amounts of heat stored by an encapsulated liquid-vapor mixture of water and of pure ammonia, excluding the container, with the heat stored by Lithium as it changes phases from solid to liquid at $820^{\circ} \mathrm{R}$. The terms $5 \%, 10 \%, 20 \%$, etc. in Fig. 2 refer to the initial interior volume percentage of the fluid that was considered. The use of the more practical waterammonia solution, which consists of various ratios of water to ammonia, provides a range of application that spans 
that of water and pure ammonia. Figure 3 shows the different specific heat capacities of water and pure ammonia for different interior volumetric fill percents. These two working fluids provide a broad range of applications for this concept from low to high temperatures.

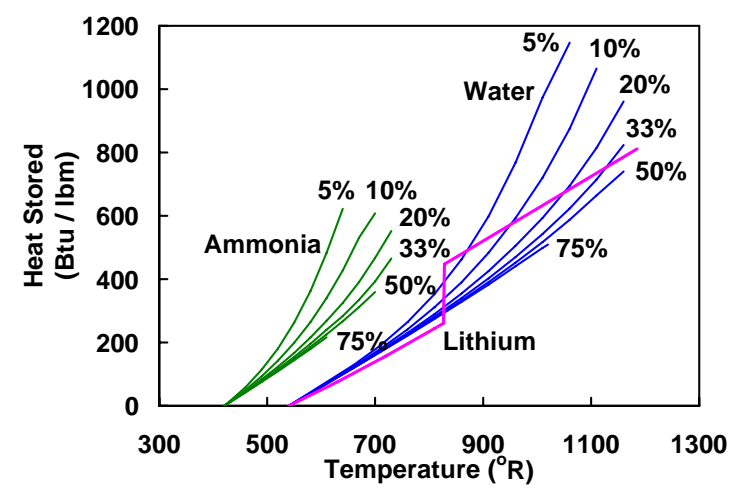

Figure 2. Heat stored by various liquid-vapor water and ammonia mixtures with varying initial interior volumetric fill percents and Lithium

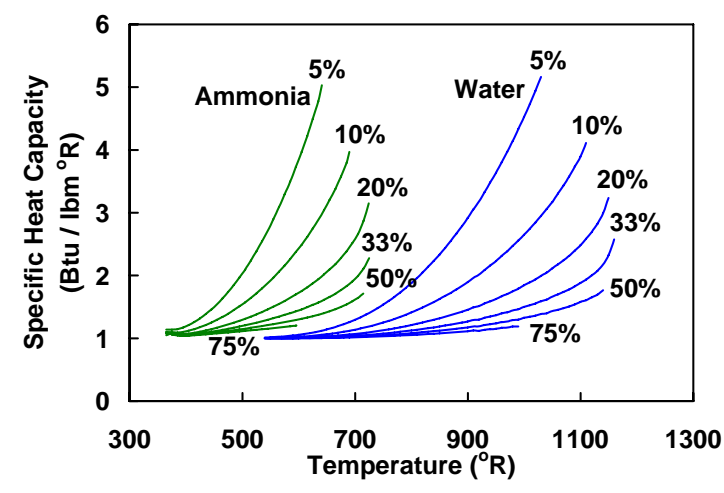

Figure 3. Specific heat capacities of various liquid-vapor water and ammonia mixtures with varying initial interior volumetric fill percents

Another important factor that must be considered is containing the pressure generated by the constant volume phase change of water and pure ammonia. The heat sponge internal system pressure for water and pure ammonia generally follows the saturation pressure curves for water and pure ammonia as shown in Fig. 4. While these pressures can rise significantly with small increases in temperature, they are manageable for most pressure vessels. In addition, the energy contained in the vessels will not be large due to the small size and nature of the vessels. Thus the failure of a pressure vessel may not be catastrophic. Pressure results will not be discussed in the present report. More details can be found in Refs. 3 and 4.

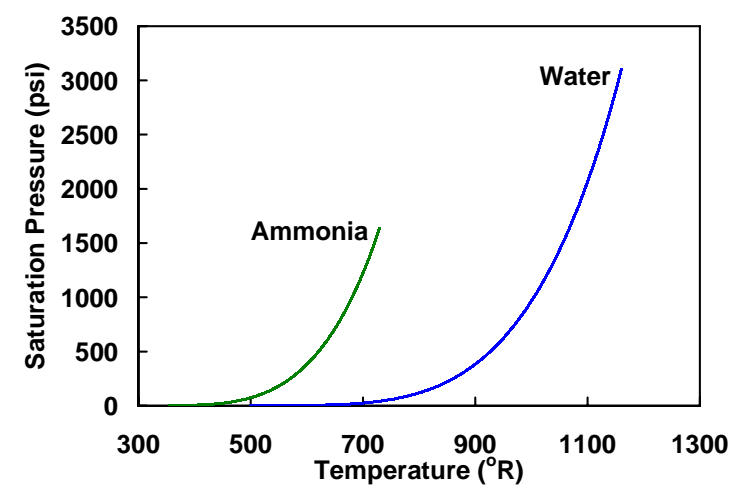

Figure 4. Heat sponge internal system pressures for water and ammonia

\section{Prototypes}

Heat sponge prototypes were developed to assess the feasibility of the concept. The prototypes needed to be large enough to be easily filled, instrumented, and handled, yet small enough to limit the stored energy and influence of the container on the overall effective specific heat capacity. Hollow, spherical specimens, 1 inch in diameter, were selected as test articles that could be readily fabricated and tested. Spherical geometry was chosen for its simplicity and efficiency at containing high pressures. Stainless steel type 304 was selected as the sphere material for its strength, resistance to corrosion, and customary use in metal spinning fabrication, a process by which metal sheets are spun and bent to form hemispherical shapes. These hemispheres were then laser welded together, to 
produce the 1-inch-diameter hollow spheres. The wall thickness of the prototype spheres were calculated by using the yield strength of $38 \mathrm{ksi}$ for 304 stainless steel, the critical pressure of 3204 psi for water, and the 1 inch constraint on the diameter of the sphere. Calculations were performed using the equation for stress in a spherical pressure vessel ${ }^{5}$ which produced an acceptable 0.020 inch nominal wall thickness. A theoretical pressure versus temperature safety analysis was performed for both water and water-ammonia filled heat sponge prototypes, the details for which can be found in Refs. 3 and 4. A water-ammonia solution was used instead of pure ammonia due to associated storage and handling issues.

Each hollow sphere was converted into a heat sponge test article by the following process. First, a small hole was drilled through the wall of the sphere to allow the needle of a syringe to pass through. Then for the water-filled heat sponge prototypes, a predetermined mass of water, based on the initial percentage of the interior volume to be filled and the density of water at $530^{\circ} \mathrm{R}$, was injected into the hollow sphere with the syringe. Initial interior volumetric percents of $10 \%, 20 \%, 25 \%, 33 \%$, and $60 \%$ water were chosen. Two different methods of sealing the hole for the syringe were tried for the water-filled prototypes. The first method used an epoxy patch and the second, more preferred, method used a silver solder patch. Figure 5 shows the progression of the water-filled heat sponge prototypes from a hemisphere, to a sphere, to an instrumented sphere with an epoxy patch. More details can be found in Ref. 3.

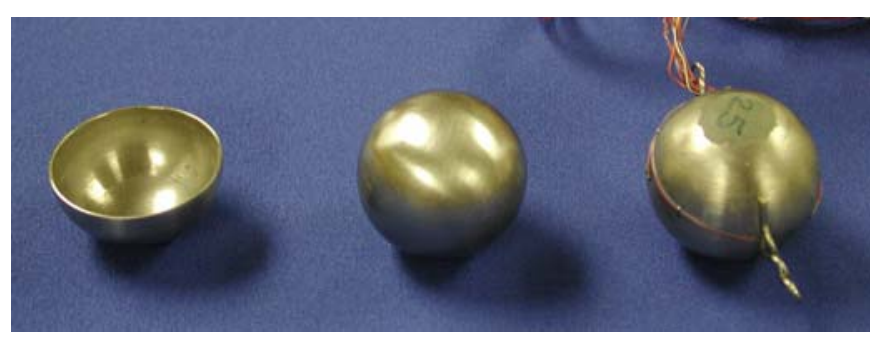

Figure 5. Heat sponge prototypes

The water-ammonia-filled heat sponge prototypes were created in a similar process as the water-filled ones. Only certain water-ammonia solutions with overall ammonia mass fractions from 0.05 to approximately 0.30 were readily available. Therefore, a water-ammonia solution was purchased with a reported overall ammonia mass fraction of 0.28 . A lower overall ammonia mass fraction of 0.14 was obtained by diluting the 0.28 with purified water during the filling process. Three water-ammonia-filled heat sponge prototypes were created, two initial interior volumetric percents of $20 \%$ and $50 \%$ with an overall ammonia mass fraction of 0.28 , and one initial interior volumetric percent of $50 \%$ with an overall ammonia mass fraction of 0.14 . Care was required to obtain and keep the desired overall ammonia mass fraction constant within the heat sponge prototypes. Ammonia readily and rapidly comes out of solution if steps are not taken to store the mixture properly ${ }^{6}$. Initial attempts to seal in the waterammonia solutions using the same epoxy and silver solder techniques as the water-filled prototypes failed to keep the ammonia in solution. After some trial and error, a modified approach using the epoxy and a 0-80 threaded screw was successful in sealing the water-ammonia solution in the heat sponge prototypes. More details can be found in Ref. 4.

\section{Experimental Approach}

The primary limitations in using available heat capacity characterization methods for characterizing the heat sponge prototype test article were its physical properties; its size, shape, and mass, coupled with its internal liquid-vapor phase change. Therefore a hybrid method and a new apparatus were designed for the characterization of the heat sponge test article's heat capacity. The method used to characterize the heat capacity of the heat sponge test article was a hybrid combination of the adiabatic and drop calorimetry methods ${ }^{3}$. Figure 6 shows the apparatus designed for this characterization method. The heating chamber consisted of a 1.5-inch-diameter, 6-inch-long cylindrically coiled cable heater which brought the test article up to a temperature of $880^{\circ} \mathrm{R}$. The test article was then transferred from the heating chamber to the cooling chamber in approximately 5 seconds by a stepper motor. The cooling chamber consisted of an 8-inch-length of straight 2 -inch-diameter copper pipe wrapped by $3 / 8$-inch-diameter copper 
tubing which brought the test article back to room temperature. The temperature in the cooling chamber was maintained by a recirculation chiller via the tubing at temperatures less than or equal to $520^{\circ} \mathrm{R}$.
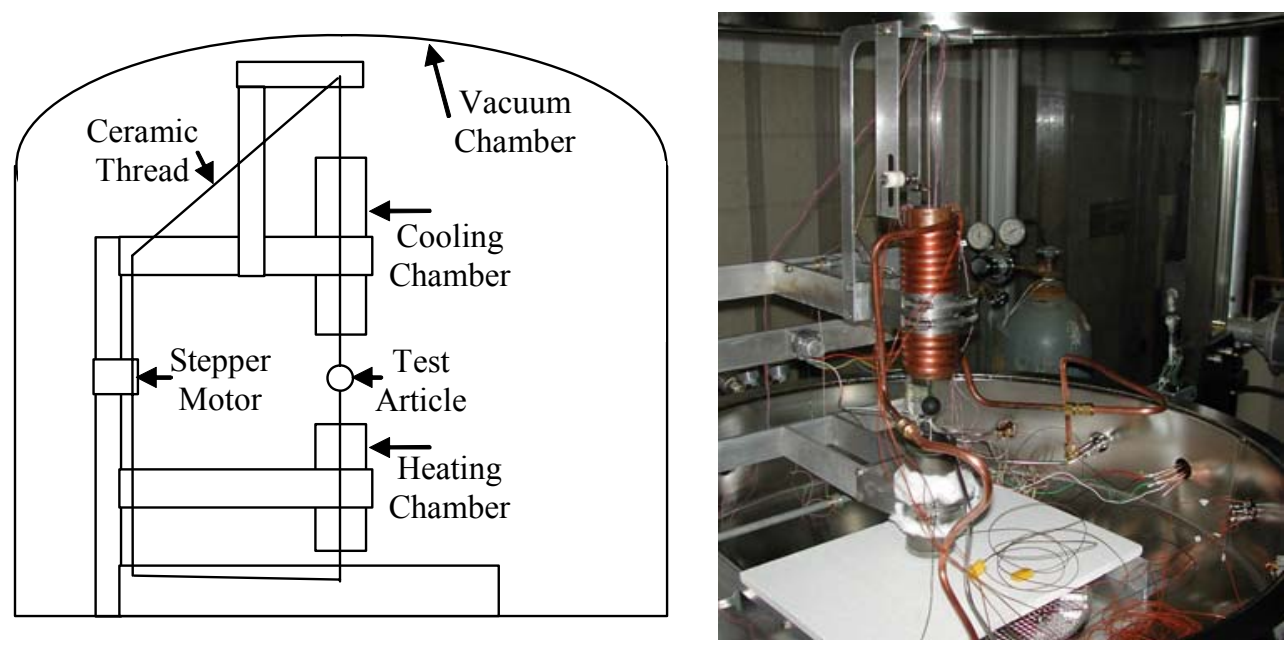

Figure 6. Heat sponge characterization apparatus

The temperature of the cable heater was monitored by three Type-K thermocouples located at the top, middle, and bottom of the cylinder. The temperature of the spherical test article was monitored by six Type-T thermocouples, five of which were evenly spaced along a single longitudinal line on one side of the sphere, and the sixth which was located at the equator on the other side of the sphere along a longitudinal line 180 degrees from the first five thermocouples as shown in Fig. 7. This thermocouple configuration was chosen because it would capture any temperature gradients on the test article which might result due to the effect of gravity on the internal liquidvapor mixture and the geometry of the test article and chambers. A strain gauge was installed on the same longitudinal line as the sixth thermocouple to determine the interior pressure of the test article. The temperature of the copper pipe in the cooling chamber was monitored by four Type-K thermocouples spaced evenly around the middle of the pipe. The temperatures recorded during the cool down of the test article were used to determine its temperature dependent specific heat capacity.

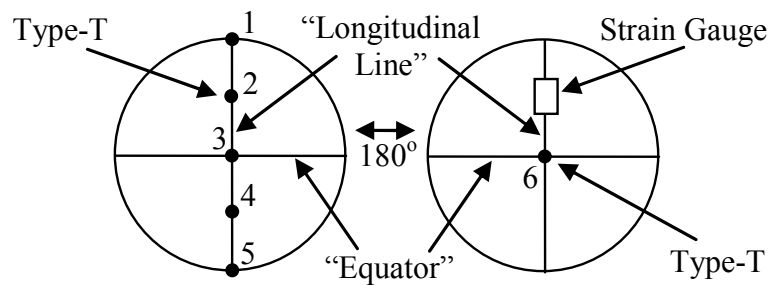

Figure 7. Heat sponge test article instrumentation

The most difficult challenge in implementing this approach was to effectively characterize the heat lost from the test article as it cooled. This task was simplified by designing the apparatus and experimental setup to eliminate or minimize all heat transfer modes except radiation. The apparatus was enclosed by a vacuum chamber at a pressure below $2 \times 10^{-4}$ torr to minimize convection and gas conduction. The test article was suspended with low-conductivity ceramic thread to minimize solid conduction. The surfaces of the test article and cylindrical chambers were painted with a high temperature optical black coating with an emissivity/absorptivity of 0.92 across the wavelengths of 0.5 $\mu \mathrm{m}$ to $20 \mu \mathrm{m}$ as reported by the manufacturer. The dimensions of both cylindrical chambers provided a shape factor of 0.97 or better from the test article to each chamber. More details can be found in Ref. 3 . 


\section{Numerical Approach}

\section{A. Heat Transfer Model}

Numerical models were developed both to predict and to evaluate the performance of the heat sponge concept. Since the optical black coatings had an emissivity/absorptivity of 0.92 over a majority of the peak infrared wavelengths, the test articles and chambers were assumed to be gray bodies. The net rate of radiation transfer in an enclosure consisting of any two gray surfaces, where the enclosed gray surface does not radiate back on itself, can be represented by Eq. (1)

$$
q_{i-j}=F_{i-j} \sigma\left(T_{i}^{4}-T_{j}^{4}\right)
$$

Where $F_{i-j}$ is an effective shape factor that combines the shape factor and emissivity for the system, $T_{i}$ is the test article temperature, and $T_{j}$ is the constant temperature of the cooling chamber.

Equation (1) is valid only if the cylinder is considered to be a single surface, because the enclosed spherical surface does not radiate back on itself ${ }^{\prime}$. However, the cylindrical chamber in this case has two holes at each end which act like black bodies at temperatures different from the cylinder wall. Instead of performing a more complex net radiation transfer analysis for a sphere enclosed by a multi-surface concentric cylinder, it was decided and shown in Ref. 3, that Equation (1) was a good approximation of the net radiation exchanged for these experiments. The term $F_{i-j}$ was quantified experimentally as an effective shape factor for the system through the calibration of the apparatus to a solid aluminum 2024 sphere, which is discussed in a later subsection.

The conservation of energy principle for a control volume then provides the governing equation for this experimental analysis. The test article does not generate its own energy and any incident energy or spatial temperature variations are assumed to be negligible. The volume and surface area integrals relating to the energy stored and leaving the system are then integrated to produce Eq. $(2)^{8}$

$$
\rho C \frac{d T_{i}}{d t} V+F_{i-j} \sigma\left(T_{i}^{4}-T_{j}^{4}\right) A=0
$$

Equation (2) was used for two different purposes; the first was to predict the temperature history of the test article using a numerically calculated specific heat capacity and a fourth order Runge-Kutta scheme ${ }^{9}$, and the second was to evaluate the experimental effective specific heat capacity of the test article from measured quantities. Temperature predictions will not be discussed in the present report.

To evaluate the experimental effective specific heat capacity of the test articles, Eq. (2) was solved for $C$. The temperature derivative was approximated by using a first order centered finite-difference formula with respect to time ${ }^{9}$. The experimental effective specific heat capacity was then calculated by substituting in the average measured test article and cooling chamber temperatures for $T_{i}$ and $T_{j}$ respectively. For comparison with the experimental data, high order polynomial functions were fitted to table and chart data for the specific heat capacity of each material versus temperature ${ }^{10,11}$. The specific heat capacity versus temperature data for water and a water-ammonia solution pertaining to its phase change were generated by numerical thermodynamic models which are explained in the following subsections. The specific heat capacity of the liquid-vapor mixtures was mass averaged together with the specific heat capacity of the stainless steel container to produce an effective specific heat capacity for the heat sponge prototypes. More details can be found in Refs. 3 and 4.

\section{B. Water-Filled Heat Sponge Thermodynamic Model}

A numerical thermodynamic model was developed to calculate the specific heat capacity of a liquid-vapor water mixture as it transitioned through its phase change at a constant volume and mass. The water-filled heat sponge was modeled as a closed thermodynamic system because the liquid-vapor water system was completely enclosed by the stainless steel sphere. A simplified model neglecting air within the heat sponge sphere is shown in Fig. 8. This model assumed that the sphere contained a given initial interior volume percentage and mass of liquid water at room temperature in non-equilibrium contact with vacuum which occupies the remaining interior volume of the sphere as shown in Fig. 8a. This closed system reaches equilibrium through the evaporation of the liquid water into water vapor until the saturation pressure of the water has been reached at room temperature. This room temperature, saturated equilibrium state is called a closed saturated system, as shown in Fig. 8b, and provides the initial conditions for the water-filled heat sponge thermodynamics model. This system must follow two imposed 


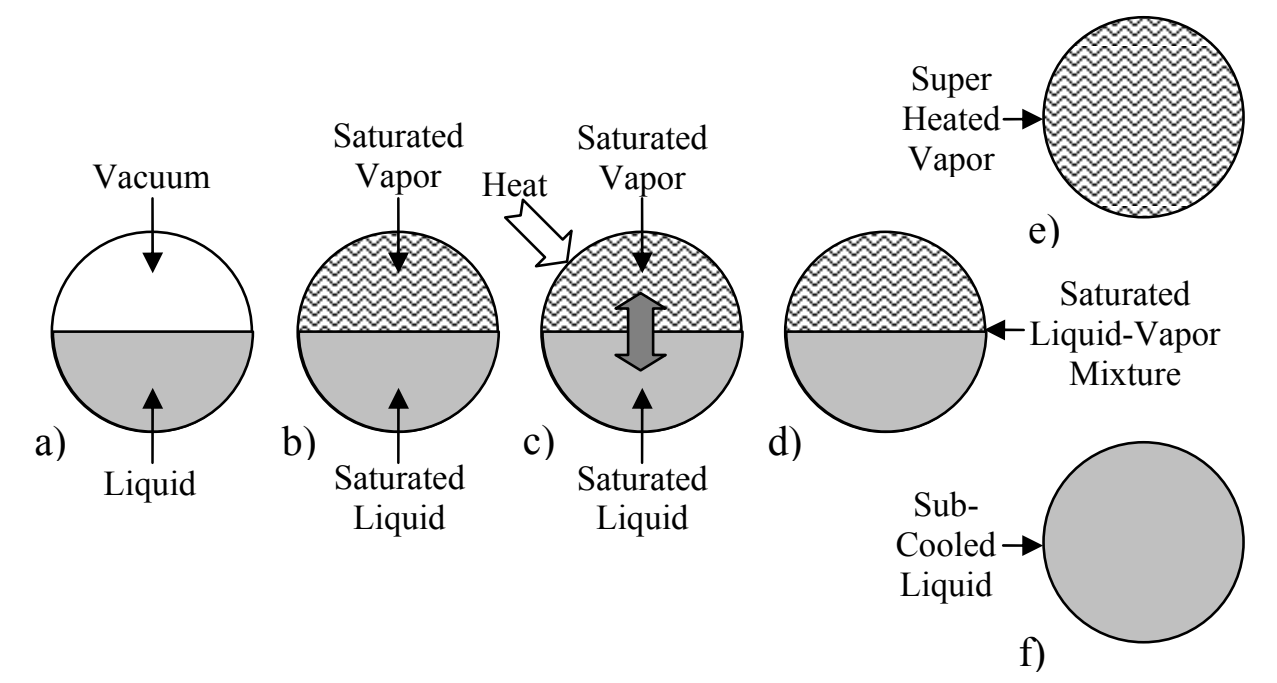

Figure 8. Ideal thermodynamic model of water-filled heat sponge

physical constraints on its mass and volume. The first physical constraint is that the total number of moles of water in the system remains constant, and the second physical constraint is that the total volume occupied by the two phases of water equals the internal volume of the sphere. An increase in the temperature of the system from room temperature by the addition of heat causes the water molecules to transfer between liquid and vapor, as shown in Fig. 8c, changing the volume and mass of the liquid water and water vapor. The changes in the liquid and vapor volumes are calculated by first linearly interpolating in the steam tables ${ }^{12,13}$ for the saturated specific volume properties of water at the new system temperature. Then these saturated specific volume properties are subjected to the physical constraints of the system to determine the new liquid and vapor volumes, and consequently the new liquid and vapor masses. Knowing the new liquid and vapor volumes and masses, the vapor volume fraction and quality of the system can be calculated for the new saturated equilibrium state corresponding to the new temperature. The saturated specific internal energy and enthalpy of the liquid and vapor components of the system are determined in the same manner as the saturated specific volume was, by interpolating in the steam tables with the new saturated system temperature. The interpolated saturated specific internal energies and enthalpies of the liquid and vapor are each combined using the quality of the system to determine the specific internal energy and specific enthalpy of the new saturated equilibrium state. This process continues until the system reaches one of three final equilibrium states for water. The first equilibrium state is a two-phase saturated mixture, as shown in Fig. $8 \mathrm{~d}$, for initial interior volume percentages of water between $20 \%$ and $50 \%$. The second state is a superheated vapor, as shown in Fig. 8e, for initial interior volume percentages of water between $1 \%$ and $20 \%$. Finally, the third state is a sub-cooled liquid, as shown in Fig. 8f, for initial interior volume percentages between $50 \%$ and $99 \%$. The specific heat capacity for the given initial interior volume percentage and mass of liquid water is then found by calculating the change in specific enthalpy versus temperature. More details can be found in Ref. 3.

\section{Water-Ammonia-Filled Heat Sponge Thermodynamic Model}

The water-ammonia-filled heat sponge was modeled as a constant volume, closed thermodynamic system with a two component solution in vapor-liquid equilibrium (VLE). It was assumed that any volume not occupied by waterammonia liquid consisted of only water-ammonia vapor. An equilibrium state is then calculated for a given system temperature by the simultaneous solution of six unknowns in six equations. The first three equations involve functions from the Helmholtz free energy (HFE) formulation for the thermodynamic properties of water-ammonia mixtures as given by Tillner-Roth and Friend ${ }^{14,15}$ in terms of the given system temperature, and the four unknown properties of the mixture; liquid density, vapor density, liquid mass fraction of ammonia, and vapor mass fraction of ammonia. Solution of these three equations guarantees that the system is in a state of thermodynamic equilibrium at the given system temperature ${ }^{14-16}$. The VLE equations with terms from the HFE formulation are

$$
\begin{gathered}
P=P\left(T, \rho^{\prime}, x\right)=P\left(T, \rho^{\prime \prime}, y\right) \\
(1-x) \phi_{1}\left(T, \rho^{\prime}, x\right)=(1-y) \phi_{1}\left(T, \rho^{\prime \prime}, y\right)
\end{gathered}
$$




$$
x \phi_{2}\left(T, \rho^{\prime}, x\right)=y \phi_{2}\left(T, \rho^{\prime \prime}, y\right)
$$

Equation (3) requires the vapor and liquid pressures to be equal. This provides the internal system pressure of the heat sponge. Equations (4) and (5) reflect the fact that VLE for a binary mixture requires the fugacity of a specific component in the liquid phase to equal the fugacity of the same component in the vapor phase ${ }^{16}$. The fugacity is commonly defined as a tendency for a component in a mixture to transition from one phase to another, in this case liquid to vapor or vapor to liquid. These equations must be solved under the constraints of three known quantities; the constant internal volume of the heat sponge, the total mass of the water-ammonia mixture, and the overall mass fraction of ammonia. Therefore, the following three equations are also required

$$
\begin{gathered}
V^{\prime}+V^{\prime \prime}=V \\
\rho^{\prime} V^{\prime}+\rho^{\prime \prime} V^{\prime \prime}=M_{W A} \\
\frac{\left(x \rho^{\prime} V^{\prime}+y \rho^{\prime \prime} V^{\prime \prime}\right)}{M_{W A}}=\chi
\end{gathered}
$$

The overall mass fraction of ammonia is defined as the sum of the mass of ammonia in the vapor and liquid states divided by the total mass of the mixture. The liquid volume and the vapor volume are the fifth and six unknown quantities. The simultaneous solution of all six equations provides a unique equilibrium state at the given system temperature. Once the equilibrium state is obtained for the given temperature, temperature is incremented and the solution process is repeated over the desired temperature range. The thermodynamic properties generated from these equilibrium states can then be used to calculate the temperature dependant specific heat capacity of the waterammonia mixture. More details can be found in Ref. 4.

\section{Experiments}

\section{A. Aluminum Calibration Experiments}

The specific heat capacity of a 1.0-inch-diameter solid aluminum 2024 sphere was characterized first using this new method and apparatus in order to validate the method and calibrate the apparatus. Aluminum 2024 was chosen because it has a high specific heat capacity for a structural material, and is inexpensive and readily available. Specific heat capacity values versus temperature for aluminum 2024 were taken from a handbook ${ }^{11}$ and fitted with a polynomial to be used as a calibration reference. Handbook values and the polynomial were assumed to be accurate and without error. Four series of tests were performed by Splinter ${ }^{3}$ and Gifford ${ }^{4}$ with this calibration sphere for temperatures between $500^{\circ} \mathrm{R}$ and $860^{\circ} \mathrm{R}$, and a calibration value for $F_{i-j}$ of 0.916 was established. Results are presented in Fig. 9 and Table 1. Figure 9 is a graphical display of the measured values overlaid with handbook values and additional bands denoting the uncertainty in the experimental measurement. Table 1 displays the average measured specific heat capacity value, the average RMS deviation of experimental value from handbook value, and the average uncertainty in the experimental measurement at each of the listed temperatures.

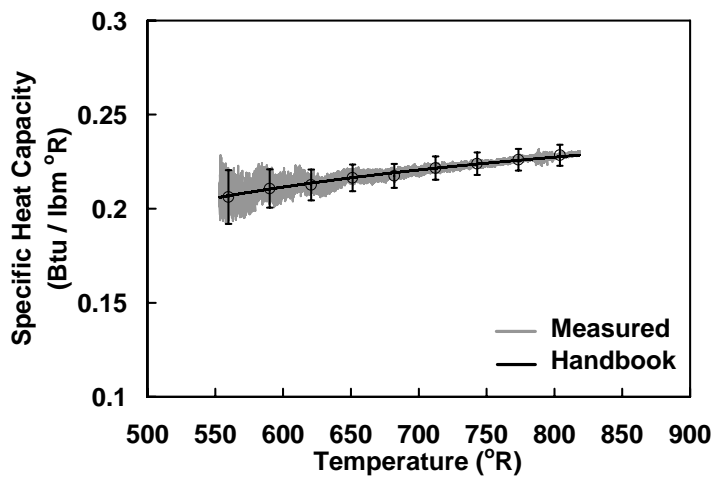

Figure 9. AL 2024 specific heat capacity results
Table 1. AL 2024 specific heat capacity results

\begin{tabular}{|c|c|c|c|}
\hline $\begin{array}{c}\text { Temp. } \\
\left({ }^{\circ} \mathrm{R}\right)\end{array}$ & $\begin{array}{c}\text { Meas. C } \\
\left(\mathrm{Btu} / \mathrm{lbm}^{\circ} \mathrm{R}\right)\end{array}$ & $\begin{array}{c}\text { RMS Dev. } \\
\left({\left.\mathrm{Btu} / \mathrm{lbm}^{\circ}\right)}{ }^{\circ}\right.\end{array}$ & $\begin{array}{c}\text { Uncertainty } \\
\left(\mathrm{Btu} / \mathrm{lbm}^{\circ} \mathrm{R}\right)\end{array}$ \\
\hline 804.01 & 0.2284 & 0.0009 & 0.0056 \\
\hline 773.44 & 0.2260 & 0.0006 & 0.0058 \\
\hline 743.00 & 0.2239 & 0.0009 & 0.0059 \\
\hline 712.33 & 0.2216 & 0.0010 & 0.0062 \\
\hline 681.85 & 0.2174 & 0.0021 & 0.0064 \\
\hline 651.17 & 0.2164 & 0.0017 & 0.0071 \\
\hline 620.65 & 0.2126 & 0.0024 & 0.0082 \\
\hline 590.12 & 0.2107 & 0.0032 & 0.0102 \\
\hline 559.65 & 0.2062 & 0.0054 & 0.0143 \\
\hline
\end{tabular}




\section{B. Water-Filled Heat Sponge Experiments}

Experimental specific heat capacity results were obtained using the validated method and apparatus for $10 \%$, $20 \%, 33 \%$, and $60 \%$ water-filled, stainless-steel, heat-sponge test articles, and were compared to their respective numerical predictions generated by the theoretical models. The $10 \%, 33 \%$, and $60 \%$ water-filled test articles were chosen because they transition to one of the final equilibrium states of the heat sponge concept; superheated vapor, saturated mixture, and sub-cooled liquid, respectively ${ }^{3}$. The $20 \%$ and a second $33 \%$ water-filled test article were chosen for additional concept characterization and comparison purposes ${ }^{17}$, respectively, after improvements had been made to the method and apparatus as discussed later in this subsection. The results for the second $33 \%$ waterfilled test article are presented in Fig. 10 and Table 2, which are similar to Fig. 9 and Table 1. Figure 11 displays the results for the $10 \%, 20 \%$, the second $33 \%$, and $60 \%$ water-filled heat sponge test articles without the uncertainty bands for clarity. Figure 11 also shows that a higher initial fill percent of water in the test article resulted in a higher overall specific heat capacity. The upward sloping trend and increased noise in the lower temperature regions of the $10 \%$ and $60 \%$ results were caused by strain gauge self-heating and a small temperature difference between the test article and cooling chamber, respectively. These effects were reduced in the $20 \%$ and second $33 \%$ water-filled test articles by performing separate tests with the strain gauge turned off and turned on to obtain specific heat capacity and pressure data respectively, and by lowering the temperature of the cooling chamber to maximize the temperature difference between it and the test article ${ }^{4}$. The numerical predictions were in close agreement with the experimental results, and were within the uncertainty of the experimental measurements. More details can be found in Ref. 3.

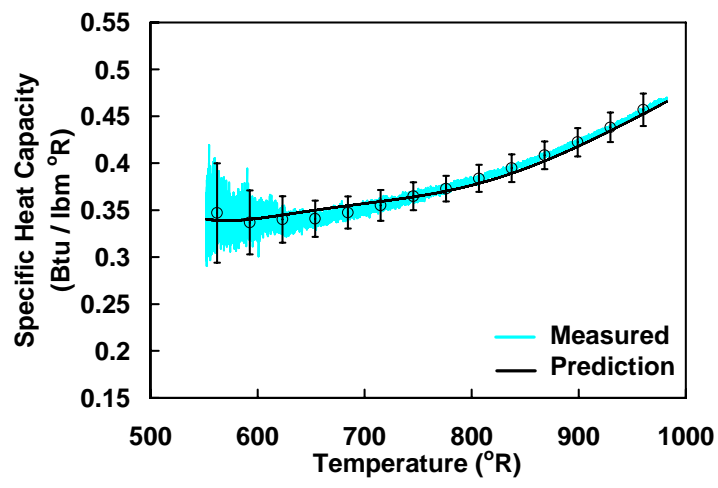

Figure 10. 33\%-II water-filled specific heat capacity results

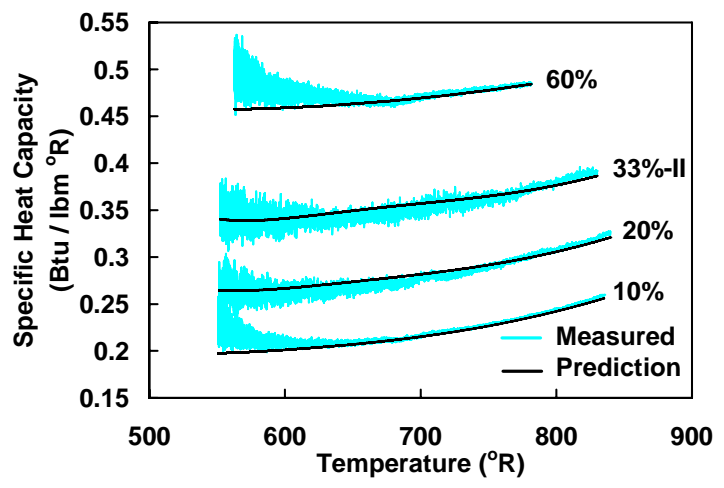

Figure 11. 10\%, 20\%, 33\%-II, \& $60 \%$ waterfilled specific heat capacity results

Table 2.33\%-II water-filled specific heat capacity results

\begin{tabular}{|c|c|c|c|}
\hline $\begin{array}{c}\text { Temp } \\
\left({ }^{\circ} \mathrm{R}\right)\end{array}$ & $\begin{array}{c}\text { Meas. C } \\
\left(\mathrm{Btu} / \mathrm{lbm}^{\circ} \mathrm{R}\right)\end{array}$ & $\begin{array}{c}\text { RMS Dev. } \\
\left(\mathrm{Btu} / \mathrm{lbm}^{\circ} \mathrm{R}\right)\end{array}$ & $\begin{array}{c}\text { Uncertainty } \\
\left(\mathrm{Btu} / \mathrm{lbm}^{\circ} \mathrm{R}\right)\end{array}$ \\
\hline 960.21 & 0.4570 & 0.0049 & 0.0173 \\
\hline 929.41 & 0.4382 & 0.0039 & 0.0158 \\
\hline 898.86 & 0.4224 & 0.0049 & 0.0151 \\
\hline 868.10 & 0.4085 & 0.0064 & 0.0147 \\
\hline 837.31 & 0.3947 & 0.0060 & 0.0148 \\
\hline 806.71 & 0.3838 & 0.0057 & 0.0144 \\
\hline 776.05 & 0.3728 & 0.0035 & 0.0137 \\
\hline 745.53 & 0.3648 & 0.0023 & 0.0148 \\
\hline 714.90 & 0.3550 & 0.0051 & 0.0164 \\
\hline 684.39 & 0.3474 & 0.0081 & 0.0171 \\
\hline 653.74 & 0.3409 & 0.0098 & 0.0194 \\
\hline 623.25 & 0.3401 & 0.0072 & 0.0248 \\
\hline 592.68 & 0.3369 & 0.0096 & 0.0341 \\
\hline 562.20 & 0.3470 & 0.0195 & 0.0529 \\
\hline
\end{tabular}




\section{Water-Ammonia-Filled Heat Sponge Experiments}

Experimental specific heat capacity results were obtained using the validated method and apparatus for three water-ammonia-filled, stainless-steel, heat-sponge test articles, and were compared to their respective numerical predictions generated by the theoretical models ${ }^{4}$. The first test article, WA1, had an initial liquid fill percentage of $50 \%$ with an overall ammonia mass fraction of 0.28 . The second test article, WA2, had an initial liquid fill percentage of $20 \%$ with an overall ammonia mass fraction of 0.28 . These two test articles were chosen to cover the transition to the final equilibrium states of superheated vapor and sub-cooled liquid for the 0.28 mixture while keeping internal system pressures manageable. The third test article, WA3, had an initial liquid fill percentage of $50 \%$ and an overall ammonia mass fraction of 0.14 . This test article was chosen for comparison with WA1 to demonstrate the effects of changing the overall mass fraction of ammonia for the same liquid fill percentage. The results for the WA1 water-ammonia filled test article are presented in Fig. 12 and Table 3, which are similar to Figs. 9 and 10, and Tables 1 and 2. Figure 13 displays the results for the WA1, WA2, and WA3 water-ammonia-filled heat sponge test articles and is similar to Fig. 11. Figure 13 also shows that a higher overall mass fraction of ammonia for the same liquid fill percentage results in a higher overall specific heat capacity. Again, the upward sloping trend and increased noise in the lower temperature regions of the WA2 results were caused by strain gauge self-heating and the small temperature difference between the test article and cooling chamber. The numerical predictions were again in close agreement with the experimental results, and were again within the uncertainty of the experimental measurements. More details can be found in Ref. 4.

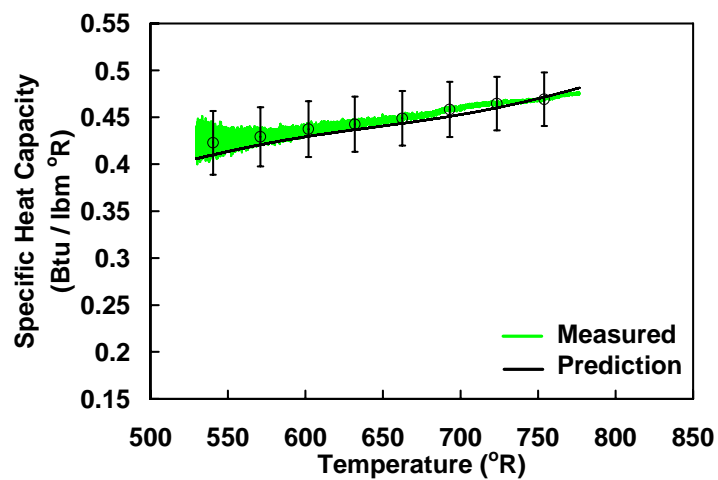

Figure 12. WA1 water-ammonia-filled specific heat capacity results

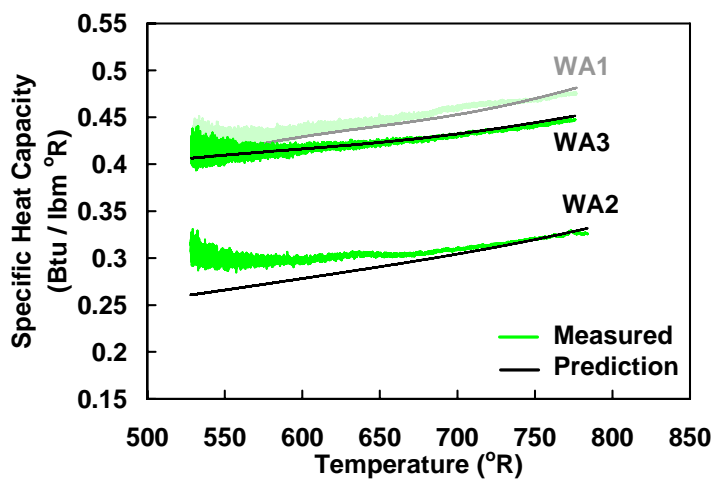

Figure 13. WA1, WA2, and WA3 waterammonia-filled specific heat capacity results

Table 3. WA1 water-ammonia-filled specific heat capacity results

\begin{tabular}{|c|c|c|c|}
\hline $\begin{array}{c}\text { Temp } \\
\left({ }^{\circ} \mathrm{R}\right)\end{array}$ & $\begin{array}{c}\text { Meas. C } \\
\left(\mathrm{Btu} / \mathrm{lbm}^{\circ} \mathrm{R}\right)\end{array}$ & $\begin{array}{c}\text { RMS Dev. } \\
\left(\mathrm{Btu} / \mathrm{lbm}^{\circ} \mathrm{R}\right)\end{array}$ & $\begin{array}{c}\text { Uncertainty } \\
\left(\mathrm{Btu}_{/} / \mathrm{bm}^{\circ} \mathrm{R}\right)\end{array}$ \\
\hline 753.98 & 0.4691 & 0.0034 & 0.0285 \\
\hline 723.49 & 0.4646 & 0.0036 & 0.0285 \\
\hline 693.01 & 0.4583 & 0.0035 & 0.0294 \\
\hline 662.43 & 0.4489 & 0.0032 & 0.0291 \\
\hline 631.87 & 0.4426 & 0.0030 & 0.0294 \\
\hline 601.38 & 0.4373 & 0.0043 & 0.0298 \\
\hline 570.94 & 0.4292 & 0.0055 & 0.0315 \\
\hline 540.38 & 0.4228 & 0.0100 & 0.0340 \\
\hline
\end{tabular}

\section{Discussion}

The prototype heat sponge test articles successfully demonstrated the potential of the heat sponge concept. These experiments showed that by containing the liquid-vapor phase change of water and a water-ammonia solution 
inside a spherical pressure vessel, the effective heat storage capacity of the vessel can be raised significantly. Verification of this can be found in a comparison of the heat stored in each of the following materials and systems; the 304 stainless steel used to fabricate the prototypes (SS 304), the 2024 aluminum used for calibration (AL 2024), the $20 \%$ water-filled heat sponge test article ( $20 \%$ Water + SS 304$)$, the $20 \%$ liquid-vapor mixture of water $(20 \%$ Water), the $20 \%$ water-ammonia-filled heat sponge test article with overall ammonia mass fraction of $0.28(20 \%$ Water-Ammonia + SS 304), and the $20 \%$ liquid-vapor mixture of water-ammonia with an overall ammonia mass fraction of 0.28 (20\% Water-Ammonia). The comparison is made by using the average specific heat capacity for each of these materials and systems at approximately $775.5^{\circ} \mathrm{R}$, and assuming a mass of $1 \mathrm{lb}$ for each with a temperature rise of $1^{\circ} \mathrm{R}$ from $775^{\circ} \mathrm{R}$ to $776^{\circ} \mathrm{R}$. The temperature of $775.5^{\circ} \mathrm{R}$ was the highest temperature for which experimental specific heat capacity data was available for comparison purposes. The specific heat capacities for each of the materials and systems are shown in Fig. 14 with a line denoting $775.5^{\circ} \mathrm{R}$. Table 4 provides the numerical value of each materials' and systems' specific heat capacity at $775.5^{\circ} \mathrm{R}$, the heat stored for each per the aforementioned basis of comparison, and the results for a specific material or system when compared to each of the other materials and systems. For instance, the heat stored by the 20\% Water + SS 304 is 1.3 times more than that of the AL 2024 when compared. Similarly, the heat stored by the $20 \%$ Water-Ammonia + SS 304 is 1.46 times more than that of the AL 2024 when compared. Thus for the same mass of each material and system, the heat sponge concept can provide a $30 \%$ to $46 \%$ increase in the amount of heat stored. The use of a water-ammonia solution instead of pure water also provides an increase in the amount of heat stored for the same amount of mass of each material and system.

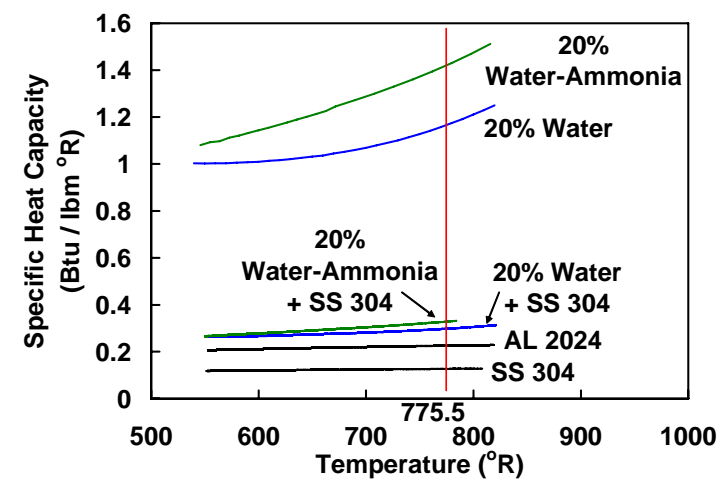

Figure 14. Specific heat capacities for various materials and systems of interest

Table 4. Heat storage comparison for various materials and systems of interest

\begin{tabular}{|c|c|c|c|c|c|c|c|c|c|}
\hline & $\begin{array}{c}\text { Temperature } \\
\text { ('R) }\end{array}$ & $\begin{array}{c}\mathrm{C} \\
(\mathrm{Btu} / \mathrm{lbm} \times \mathbf{R}) \\
\end{array}$ & $\begin{array}{c}\text { Mass }=1 \mathrm{lbm} \\
\text { DT }=1{ }^{\circ} \mathrm{R} \\
\text { Q (Btu) }\end{array}$ & $\begin{array}{c}\text { Compared to } \\
\text { SS } 304\end{array}$ & $\begin{array}{l}\text { Compared to } \\
\text { AL 2024 }\end{array}$ & $\begin{array}{c}\text { Compared to } \\
20 \% \text { Water } \\
+ \text { SS } 304 \\
\end{array}$ & $\begin{array}{c}\text { Compared to } \\
20 \% \text { Water- } \\
\text { Am. + SS } 304 \\
\end{array}$ & $\begin{array}{c}\text { Compared to } \\
20 \% \text { Water }\end{array}$ & $\begin{array}{c}\text { Compared to } \\
20 \% \text { Water- } \\
\text { Ammonia } \\
\end{array}$ \\
\hline SS 304 & 775.5 & 0.13 & 0.13 & 1.00 & 0.56 & 0.43 & 0.39 & 0.11 & 0.09 \\
\hline AL 2024 & 775.5 & 0.23 & 0.23 & 1.78 & 1.00 & 0.77 & 0.69 & 0.19 & 0.16 \\
\hline $20 \%$ Water + SS 304 & 775.5 & 0.29 & 0.29 & 2.32 & 1.30 & 1.00 & 0.90 & 0.25 & 0.21 \\
\hline $\begin{array}{c}20 \% \text { Water-Ammonia + } \\
\text { SS } 304 \\
\end{array}$ & 775.5 & 0.33 & 0.33 & 2.59 & 1.46 & 1.12 & 1.00 & 0.28 & 0.23 \\
\hline $20 \%$ Water & 779.6 & 1.17 & 1.17 & 9.24 & 5.20 & 3.99 & 3.57 & 1.00 & 0.82 \\
\hline $20 \%$ Water-Ammonia & 779.6 & 1.43 & 1.43 & 11.26 & 6.33 & 4.86 & 4.35 & 1.22 & 1.00 \\
\hline
\end{tabular}

Also apparent upon careful examination of Fig. 14 and Table 4 is how much the stainless steel container reduces the overall specific heat capacity of the liquid-vapor mixture in the heat sponge concept. The heat stored by the $20 \%$ Water is almost 4 times that of the $20 \%$ Water + SS 304 for the same amount of mass. Similarly, the heat stored by the $20 \%$ Water-Ammonia is 4.35 times that of the $20 \%$ Water-Ammonia + SS 304 for the same amount of mass. Thus, there is a tremendous increase in the heat storage potential of the heat sponge concept if a more efficient method of encapsulation can be devised. 


\section{Conclusion}

The heat sponge concept has been developed and verified as a mass-efficient heat storage device for enhancing the specific heat capacity of a vehicle structure. Water and a water-ammonia solution were investigated as working fluids for the heat sponge concept providing a range of application from low to high temperatures. Water-filled heat sponge prototypes were fabricated with initial interior volumetric percents of $10 \%, 20 \%, 33 \%$, and $60 \%$ water. Water-ammonia-filled heat sponge prototypes were fabricated with initial interior volumetric percents of $20 \%$ and $50 \%$ water-ammonia solution with an overall ammonia mass fraction of 0.28 , and $50 \%$ water-ammonia solution with an overall ammonia mass fraction of 0.14 . These prototypes were characterized using the hybrid method and new apparatus developed in the present report. The measured results from these characterization tests were then successfully compared to predicted results from the numerical models, thus validating the models. The heat sponge concept displayed an increased heat storage capacity when compared with other materials, and has the potential for more significant heat storage capacity should a more efficient method of encapsulation be devised. The heat sponge concept and numerical models as developed in this report can be used in future thermal protection system design efforts.

\section{References}

${ }^{1}$ Myers, D. E., Martin, C. J., and Blosser, M. L., "Parametric Weight Comparison of Advanced Metallic, Ceramic Tile, and Ceramic Blanket Thermal Protection Systems,” NASA TM-2000-210289, June 2000.

${ }^{2}$ Blosser, M. L., “Advanced Metallic Thermal Protection Systems for Reusable Launch Vehicles,” Ph.D. Dissertation, Dept. of Mechanical and Aerospace Engineering, Univ. of Virginia, Charlottesville, VA, May 2000.

${ }^{3}$ Splinter, S. C., "Characterization and Evaluation of a Mass Efficient Heat Storage Device," Master's Thesis, Dept. of Mechanical and Aerospace Engineering, The George Washington Univ., Washington D.C., August 2004.

${ }^{4}$ Gifford, A. R., "Further Development of the Heat Sponge Concept Using Water-Ammonia Mixtures," Master's Thesis, Dept. of Mechanical and Aerospace Engineering, The George Washington Univ., Washington, D.C., January 2005.

${ }^{5}$ Beer, F. P., and Johnston, E. R. Jr., Mechanics of Materials, $2^{\text {nd }}$ Ed., McGraw-Hill, New York, 1992.

${ }^{6}$ Lange's Handbook of Chemistry, $13^{\text {th }}$ Ed., Edited by Dean, J., A., McGraw-Hill, New York, 1985.

${ }^{7}$ Kreith, F., and Bohn, M. S., Principles of Heat Transfer, $6{ }^{\text {th }}$ Ed., Brooks/Cole, Pacific Grove, CA, 2001.

${ }^{8}$ Incropera, F. P., and DeWitt, D. P., Fundamentals of Heat and Mass Transfer, $4^{\text {th }}$ Ed., John Wiley \& Sons, New York, 1996.

${ }^{9}$ Chapra, S. C., and Canale, R. P., Numerical Methods for Engineers, $3{ }^{\text {rd }}$ Ed., McGraw-Hill, New York, 1998.

${ }^{10}$ Brown, W. F. Jr., Mindlin, H., and Ho, C. Y., Department of Defense, Aerospace Structural Metals Handbook, Vol. 2 , Purdue Research Foundation, West Lafayette, IN, 1994.

${ }^{11}$ Brown, W. F. Jr., Mindlin, H., and Ho, C. Y., Department of Defense, Aerospace Structural Metals Handbook, Vol. 3 , Purdue Research Foundation, West Lafayette, IN, 1994.

${ }^{12}$ Moran, M. J. and Shapiro, H. N., Fundamentals of Engineering Thermodynamics, $4^{\text {th }}$ Ed., John Wiley \& Sons, New York, 2000.

${ }^{13}$ Keenan, J. H., Keyes, F. G., Hill, P. G., and Moore, J. G., Steam Tables, Thermodynamic Properties of Water Including Vapor, Liquid, and Solid Phases (English Units), John Wiley Sons, New York, 1969.

${ }^{14}$ Tillner-Roth, R., and Friend, D. G., "A Helmholtz Free Energy Formulation of the Thermodynamic Properties of the Mixture \{Water + Ammonia\}," J. Phys. Chem. Ref. Data, Vol. 27, No. 1, 1997, pp. 63-96.

${ }^{15}$ International Association for the Properties of Water and Steam (IAPWS), "Guideline on the IAPWS Formulation 2001 for the Thermodynamic Properties of Ammonia-Water Mixtures,” Gaithersburg, MD, Sept. 2001.

${ }^{16}$ Elliot, J. R., and Lira, C. T., Introductory Chemical Engineering Thermodynamics, Prentice Hall PTR, Upper Saddle River, NJ, 1999.

${ }^{17}$ Splinter, S. C., Blosser, M. L., and Gifford, A. R., "Characterization and Evaluation of a Mass Efficient Heat Storage Device," Proceedings of the $29^{\text {th }}$ International Thermal Conductivity Conference and the $17^{\text {th }}$ International Thermal Expansion Symposium, Birmingham, AL, June 2007. 